\title{
Clinical predictors for a complicated course of disease in an inception cohort of patients with ulcerative colitis: results from the prospective, observational EPICOL study
}

\author{
Carsten Schmidt ${ }^{1,2}$ - Bernd Bokemeyer ${ }^{3} \cdot$ Andreas Lügering $^{4} \cdot$ Dominik Bettenworth ${ }^{5} \cdot$ Niels Teich $^{2,6}$. \\ Imma Fischer $^{7}$. Leonie Hammer ${ }^{8}$. Stefanie Kolterer ${ }^{8}$. Stefan Rath ${ }^{8} \cdot$ Andreas Stallmach $^{9}$. on behalf of the EPICOL \\ Study Group
}

Accepted: 16 January 2022 / Published online: 27 January 2022

(c) The Author(s) 2022

\begin{abstract}
Purpose The clinical course of ulcerative colitis (UC) is highly heterogeneous, with 20 to $30 \%$ of patients experiencing chronic disease activity requiring immunosuppressive or biologic therapies. The aim of this study was to identify predictors for a complicated disease course in an inception cohort of patients with UC.

Methods EPICOL was a prospective, observational, inception cohort (UC diagnosis, $\leq 6$ months) study in 311 patients with UC who were naive to immunosuppressants (IS)/biologics. A complicated course of disease was defined as the need for IS and/or biologic treatment (here therapy with a TNF- $\alpha$ antagonist) and/or UC-related hospitalisation. Patients were followed up for 24 months.

Results Of the 307 out of 311 participants (4 patients did not meet the inclusion criteria "confirmed diagnosis of active UC within the last 6 months" ( $n=2)$ and "immunosuppressive-naïve" $(n=2)$, analysis population), 209 (68.1\%) versus $98(31.9 \%)$ had an uncomplicated versus a complicated disease course, respectively. In a multivariate regression analysis, prior use of corticosteroids and prior anaemia were associated with a significantly increased risk for a complicated disease course (2.3- and 1.9-fold increase, respectively; $p<0.001$ and $p=0.002$ ). Based on these parameters, a risk model for patient stratification was developed.

Conclusion Our study identifies anaemia and an early need for corticosteroids as predictors for a complicated course of disease in an inception cohort of patients with UC. By determining these parameters in routine clinical practice, our results may support the identification of patients who might benefit from early escalation of therapy.
\end{abstract}

Keywords Ulcerative colitis $\cdot$ Complicated disease $\cdot$ Predictors $\cdot$ Immunosuppressant $\cdot$ TNF- $\alpha$ antagonist $\cdot$ Biologics

\section{Introduction}

Ulcerative colitis (UC) is an inflammatory bowel disease (IBD) characterised by colonic inflammation extending proximally from the rectum [1]. Depending on disease

Carsten Schmidt

carsten.schmidt@klinikum-fulda.de

1 Medical Clinic II, Fulda Hospital, Pacelliallee 4, Fulda 36043, Germany

2 Medical Faculty of the Friedrich Schiller University, Jena, Germany

3 Interdisciplinary Crohn and Colitis Centre, Minden, Germany

4 MVZ Portal 10, Münster, Germany localisation, UC may present as proctitis, left-sided colitis, or pancolitis [2]. Recurrent disease flares can lead to accumulating intestinal damage with long-term consequences, such as toxic megacolon and colectomy as well as an increased risk of colorectal cancer [3, 4].

Practice for Internal Medicine, Münster, Germany

Practice for Internal Medicine, Leipzig, Germany

Biostatistik-Tuebingen, Tübingen, Germany

8 Medical Department, AbbVie Deutschland GmbH \& Co. KG, Wiesbaden, Germany

9 Clinic for Internal Medicine IV, Jena University Hospital, Jena, Germany 
Conventional management of UC is based on a step-up approach in which treatment is continually escalated if the therapeutic goals are not reached [5, 6]. Aminosalicylates, such as 5-aminosalicylic acid (5-ASA) with oral or rectal administration, are used as first-line medication, followed by oral or intravenous corticosteroid treatment if the disease remains uncontrolled. Patients with steroid dependency and frequent relapses can subsequently be treated with immunosuppressants (IS)/immunomodulators and advanced therapies, such as tumour necrosis factor- $\alpha$ (TNF- $\alpha$ ) antagonists, anti-integrin antibodies, interleukin-12/23 antagonists, or Janus kinase inhibitors [5, 6].

Increasing evidence demonstrates the progressive nature of UC and thus emphasises the need for tight disease control that goes beyond the treatment of symptoms to avoid long-term accumulation of intestinal damage [7-9]. Updated treatment goals therefore comprise steroid-free remission as well as a normal quality of life and suggest objective indicators of disease activity, such as endoscopic remission [10]. Because achieving these therapeutic targets in patients with moderate to severe UC is often difficult, early initiation of IS or biologic treatment should be considered in patients with high risk for a complicated disease course $[6,11]$. Therefore, early identification of patients who are at an increased risk for a complicated disease course is needed to be able to initiate appropriate therapy.

To enable effective identification of at-risk patients in daily clinical practice, easily assessable parameters for the prediction of individual disease courses are necessary. Numerous studies have already aimed to address this issue $[12,13]$. Among others, these studies have identified young age at diagnosis, male sex, extensive colitis, severe endoscopic activity, and steroid dependency/resistance as predictors for hospitalisation, colectomy, and other complications [14-22]. As a result, risk stratification based on such parameters has been incorporated into various clinical decision guidelines $[6,23]$.

Despite this progress, many important questions and challenges remain. First, although the previously mentioned high-throughput techniques hold great promise, it will likely take many years before they can be established in routine clinical use, where cost and time are important limiting factors. Second, many studies on predictive parameters are retrospective and validation from prospective designs is frequently lacking. Finally, many investigated cohorts had a considerable disease duration or had already experienced some form of complications or therapy intensification. Predicting long-term outcomes based on prior events, such as hospitalisations, is certainly useful, but such complications should ideally be avoided in the first place by immediately identifying at-risk patients at diagnosis or shortly thereafter. Therefore, more studies in inception cohort patients are needed.
Here, we describe the results of EPICOL (Early Predictive Parameters of Immunosuppressive Therapy in Ulcerative Colitis). As with the forerunner study, EPIC, we aimed to prospectively validate numerous clinical predictors for a complicated disease course in patients recently diagnosed with UC, focusing in particular on parameters that are readily assessable in everyday clinical practice.

\section{Materials and methods}

\section{Study design}

EPICOL was a non-interventional, prospective, multicentre, observational study in 311 patients with UC as inception cohort (diagnosis, $<6$ months) conducted between March 2015 and April 2020. All patients were naive to IS and biologics. Patients were enrolled consecutively at centres representing different levels of care, including outpatient hospital centres and gastroenterological practices in Germany. The endpoints were frequency of UC-related hospitalisation and therapy with IS or initiation of anti-TNF- $\alpha$ therapy. Six visits were scheduled: one at baseline and one each after 3, 6, 12, 18, and 24 months. Any unscheduled visit to a physician, outpatient visits to a hospital, or hospitalisation related to the UC diagnosis were documented as unscheduled visits. Patient demographics, such as age, sex, height, tobacco use, family members with UC, and medical history (e.g. date of first UC symptoms, date of UC diagnosis, previous and current use of non-immunosuppressive UC medication) were collected retrospectively for the status of diagnosis and documented at the baseline visit. In addition, disease symptoms and UC-related extraintestinal manifestations (EIMs), such as pyoderma gangrenosum, erythema nodosum, uveitis/iritis, arthralgia/arthritis, and ankylosing spondylitis, were assessed at every visit and collected retrospectively for the status of diagnosis. Weight and weight loss, localisation of disease, current surgical status, and UC medication or changes in medication (both IS/biologic and non-IS medication) were documented for every visit. Laboratory parameters (anaemia, platelets, faecal calprotectin, C-reactive protein, colonoscopy results, and disease activity according to the simple clinical colitis activity index (SCCAI)) were determined for every visit, if available. All above-mentioned parameters except patient demographics were assessed again at every visit after the baseline visit. The time interval until the need for IS and/or anti-TNF- $\alpha$ therapy and/or UC-related hospitalisation was documented.

EPICOL is a prospective study with the same design as the recently published EPIC (Early Predictive Parameters of Immunosuppressive Therapy in Crohn's Disease) study, in which we investigated clinical parameters for their predictive power regarding the disease course in patients with 
recently diagnosed Crohn's disease $(\mathrm{CD})$ who were naive to treatment with both IS and biologics [24]. In that prospective cohort, we found that a complicated disease course, defined as the need for IS and/or anti-TNF- $\alpha$ treatment and/or CDrelated hospitalisation, was significantly associated with various baseline criteria, namely, age at diagnosis $<40$ years, anaemia, and treatment with systemic corticosteroids at first flare. Based on these parameters, a risk model in CD was developed that predicted a complicated disease course in our cohort with an accuracy of $87.2 \%$.

\section{Patient population}

In total, 311 patients with a confirmed diagnosis of active UC (except proctitis) no sooner than 6 months before the baseline visit who were $\geq 18$ years of age, naive to treatment with conventional IS (thiopurines, calcineurin inhibitors, or equivalent therapy) and biologics (adalimumab, golimumab, infliximab, vedolizumab) at the baseline visit were enrolled consecutively. Pregnant women or patients with previous UC-related surgery were excluded from the study. Note that the use of tofacitinib and ustekinumab for UC was not approved in Europe until July 2018 and September 2019, respectively.

\section{Statistical analysis}

Demographic and anamnestic data as well as case history and medication use were analysed descriptively. Mann-Whitney $U$ tests, Fisher exact tests, and chi-square tests were conducted for comparison of the two groups (patients with vs without need for hospitalisation or immunosuppressive therapy).

To analyse predictive factors for the need of IS or hospitalisation within 24 months, uni- and multivariate Cox regression analyses were performed. Predictive factors considered overall were sex and clinical response to corticosteroid therapy; predictive factors at diagnosis were age and anaemia; at baseline visit were disease severity (SCCAI), Mayo endoscopic subscore of 3 (severe), and thrombocytosis; and at diagnosis or baseline visit were therapy with systemic corticosteroids, EIM, and smoking status. For the multivariate complete Cox regression model, the factors were examined with regard to co-linearity and interaction. Reduced Cox regression model was established with all factors, with $p<0.05$ within univariate or multivariate complete Cox regression models. Parameters that were significant with $p<0.05$ in this reduced model were then selected on a stepwise basis to obtain an optimised model. Based on the optimised model, a predictive risk model was developed to determine an individual patient's probability of experiencing a complicated disease course at 6,12 , or 24 months.

\section{Results}

\section{Patient characteristics and disease course}

In total, an inception cohort of 311 patients with a recent diagnosis of UC (median time since diagnosis, 1.9 months) was enrolled in the study. Four patients who did not meet inclusion criteria were excluded ("confirmed diagnosis of active UC within the last 6 months" $(n=2)$ and "immunosuppressive-naïve" $(n=2))$, and the final analysis population consisted of 307 patients with UC (Fig. 1). Baseline characteristics of the analysis population are shown in Table 1 . The mean age was 38.5 years, and $44.6 \%(n=137)$ were female.

Approximately $50 \%$ of all participants had pancolitis; $25 \%$ were diagnosed with left-sided colitis and $25 \%$ with proctosigmoiditis (Table 2). Regarding the disease history at diagnosis, extraintestinal manifestations were reported for roughly $7 \%$ of all participants, of which the most common were arthralgia/arthritis (5.9\%). About one fifth of all patients had a documented history of anaemia $(n=58)$, and weight loss was reported for 93 (30.3\%) participants. No history of tobacco use was reported for 184 (59.9\%) patients, with $46(15.0 \%)$ and $76(24.8 \%)$ being current and former tobacco users, respectively.

Figure 1 depicts the patient disposition and the proportion of patients with need for IS and/or anti-TNF- $\alpha$ therapy and/ or hospitalisation. Of the 307 patients in the analysis population, 209 (68.1\%) were neither hospitalised nor received immunosuppressive therapy and were thus classified as having an uncomplicated disease course (group 1). In contrast, 98 (31.9\%) patients were classified as having a complicated disease course, requiring hospitalisation and/or IS and/or anti-TNF- $\alpha$ therapy (group 2). Within group 2, 56 (57.1\%) were treated with anti-TNF- $\alpha$ therapy either with or without IS, and 42/98 (42.9\%) received immunosuppressive monotherapy with azathioprine.

When assessing prior medication, we found that 264 (86.0\%) patients had been exposed to non-immunosuppressive therapy, the most common of which was 5-ASA (Table 3). Topical 5-ASA use was reported by 110 (41.7\%) patients, and 226 (85.6\%) participants reported receiving oral 5-ASA formulations. Prior use of oral budesonide and systemic corticosteroids was documented for 49 (18.6\%) and $108(40.9 \%)$ patients, respectively.

At baseline, the mean \pm SD disease activity score for the entire cohort as assessed through SCCAI was $3.83 \pm 3.16$ (Table 4). At baseline, 195 patients (63.5\%) were in clinical remission (defined as SCCAI score $<5$ ). The average SCCAI score decreased during the 24-month study period, reaching $1.86 \pm 2.4$ after 12 months and $1.30 \pm 2.10$ after 24 months. At the end of the study period, all but 11 patients $(n=190)$ were in clinical remission. 
Fig. 1 Patient disposition and analysis population. Reasons for exclusion $(n=4)$ were "confirmed diagnosis of active UC within the last 6 months" $(n=2)$ and "immunosuppressantnaive" ( $(n=2)$. IS, immunosuppressants; TNF- $\alpha$, tumour necrosis factor- $\alpha$

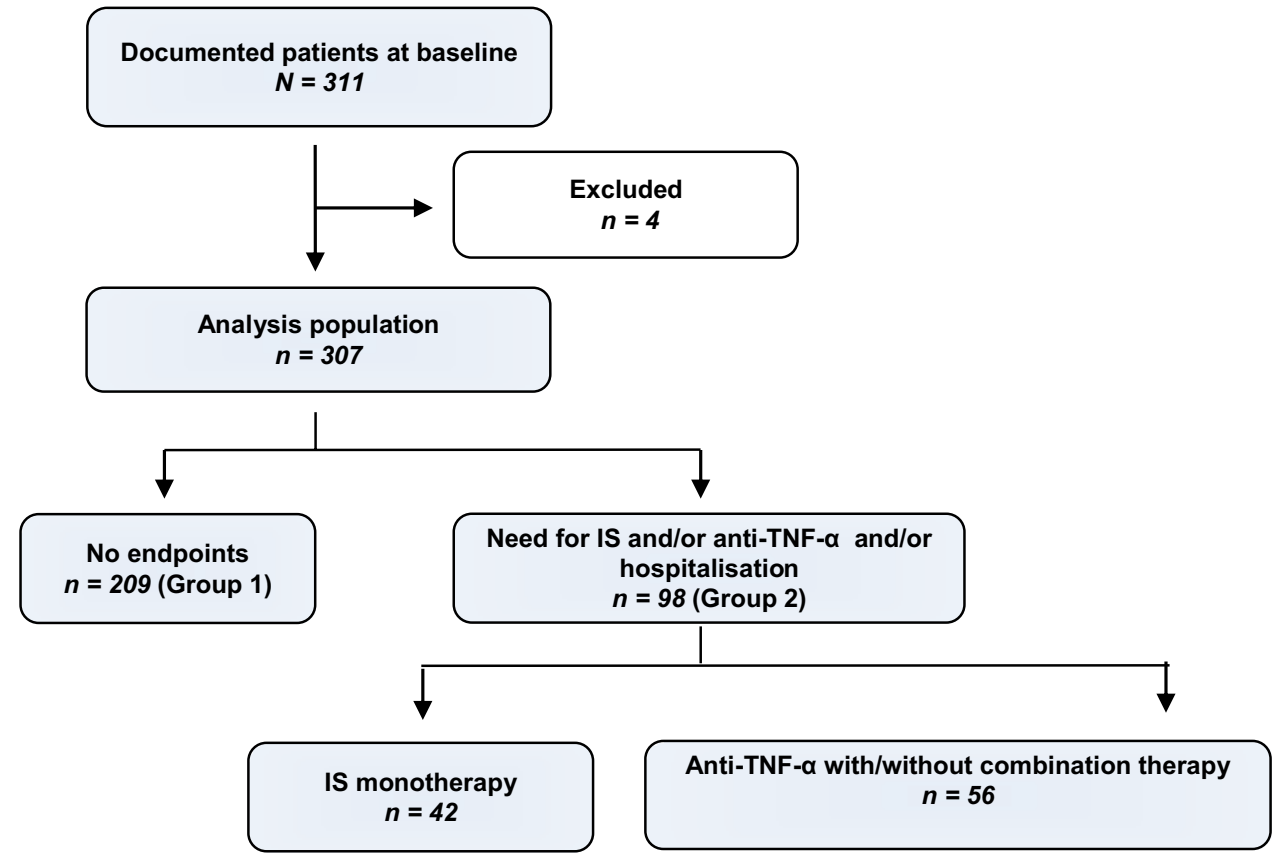

Of the 98 patients requiring immunosuppressive therapy, $56(57.1 \%)$ were treated with TNF antibodies (adalimumab, golimumab, infliximab); 42 received monotherapy with azathioprine. The median time from baseline until initiation of immunosuppressive therapy was 5.3 months. Of all patients, $23.1 \%(n=71)$ required at least one unscheduled visit to a physician, with one patient needing 13 unscheduled visits.

\section{Predictive parameters for a complicated disease course}

Examining potential differences of baseline characteristics, we found that patients with a complicated disease course were younger (mean age, 35.7 vs 39.8 years, $p=0.02$ Mann-Whitney $U$ test), and more frequently reported weight reduction $(45.9 \%$ vs $23.0 \%, p<0.001$, chi-square

Table 1 Patient characteristics at baseline

\begin{tabular}{lc}
\hline Parameter & $\begin{array}{l}\text { Patients } \\
n=307\end{array}$ \\
\hline Age, years & $38.5 \pm 15.6$ \\
Symptom duration, months & $13.6 \pm 32.6$ \\
Time since diagnosis, months & $1.9 \pm 1.9$ \\
BMI, $\mathrm{kg} / \mathrm{m}^{2} ; n=279$ & $25.2 \pm 5.2$ \\
Weight, kg; $n=280$ & $77.2 \pm 19.8$ \\
Current smoker, years; $n=43$ & $15.5 \pm 11.3$ \\
Time since stopped smoking, years; $n=66$ & $6.6 \pm 7.3$ \\
Faecal calprotectin, $\mu \mathrm{g} / \mathrm{g} ; n=80$ & $886.4 \pm 1123.2$ \\
CRP, mg/L; $n=40$ & $33.4 \pm 65.3$ \\
\hline
\end{tabular}

All data are mean \pm SD unless otherwise indicated

$B M I$ body mass index, $C R P$ C-reactive protein test) at the time of diagnosis than patients with an uncomplicated disease course. Moreover, they had higher rate of severe Mayo endoscopic scores at baseline ( $p=0.033$; Supplementary Table S1). We performed a logistic regression analysis to identify baseline parameters that are predictive

Table 2 Disease location and selected parameters

\begin{tabular}{ll}
\hline Parameter & $n(\%)$ \\
\hline Disease location at diagnosis & \\
Proctosigmoiditis & $76(24.8)$ \\
Left-sided colitis & $76(24.8)$ \\
Extensive colitis & $154(50.2)$ \\
N/A & $1(0.3)$ \\
History of extraintestinal manifestations at diagnosis & \\
Arthralgia/arthritis & $18(5.9)$ \\
Uveitis & $3(1.0)$ \\
Erythema nodosum & $1(0.3)$ \\
Anaemia at baseline & \\
Yes & $58(18.9)$ \\
No & $190(61.9)$ \\
N/A & $59(19.2)$ \\
Weight reduction at diagnosis & \\
Yes & $93(30.3)$ \\
No & $209(68.1)$ \\
N/A & $5(1.6)$ \\
Tobacco use at baseline & \\
No & $184(59.9)$ \\
Yes & $46(15.0)$ \\
Former & $76(24.8)$ \\
N/A & $1(0.3)$ \\
\hline
\end{tabular}

N/A, not available 
Table 3 Non-immunosuppressive medication at baseline

\begin{tabular}{lll}
\hline Parameter & \multicolumn{2}{l}{$\begin{array}{l}\text { Non-immunosuppressive } \\
\text { medication, } n(\%) \\
(n=264)\end{array}$} \\
\cline { 2 - 3 } & Yes & No \\
\hline 5-ASA & & $154(58.3)$ \\
Topic & $110(41.7)$ & $38(14.4)$ \\
Oral & $226(85.6)$ & $215(81.4)$ \\
Budesonide, oral & $49(18.6)$ & $156(59.1)$ \\
Systemic corticosteroids & $108(40.9)$ & \\
\hline
\end{tabular}

5-ASA, 5-aminosalicylic acid

of a complicated disease course. A list of all examined prognostic factors is provided in Table 4. For this analysis, we relied on the measurements performed at the baseline visit, except for corticosteroid use, which here refers to not only corticosteroid use at baseline but also to previous UC-related corticosteroid use by the patient.

In a first step, all demographic and anamnestic parameters observed in $\geq 5 \%$ of patients were analysed with regard to a potential predictive value in both uni- and multivariate regression models (Table 5). All parameters with $p<0.05$ in either the uni- or multivariate model (age, male sex, use of corticosteroids, anaemia, and severe Mayo endoscopic subscore of 3 points) were then included in a second multivariate model (Table 6). Parameters that were significant at $p<0.05$ in this reduced model were then stepwise selected to be included in an optimised mode. In this final model, prior use of corticosteroids and anaemia were associated with a 2.3and 1.9-fold increased risk for subsequent need for immunosuppressive therapy and/or hospitalisation, respectively.
Table 4 Potential prognostic factors evaluated at diagnosis or baseline visit

\begin{tabular}{|c|c|c|c|}
\hline \multirow[t]{2}{*}{ Parameter } & \multicolumn{3}{|c|}{ Analysis population } \\
\hline & $\begin{array}{l}\text { Total patients } \\
\quad(n=307)\end{array}$ & $\begin{array}{l}\text { Uncomplicated disease } \\
\text { course }(n=209)\end{array}$ & $\begin{array}{l}\text { Complicated } \\
\text { disease course } \\
(n=98)\end{array}$ \\
\hline Age (years, mean \pm SD) & $38.5 \pm 15.6$ & $39.8 \pm 15.8$ & $35.7 \pm 14.7$ \\
\hline \multicolumn{4}{|l|}{ Sex } \\
\hline Male & $170(55.4)$ & $110(52.6)$ & $60(61.2)$ \\
\hline Female & $137(44.6)$ & $99(47.4)$ & $38(38.8)$ \\
\hline $\begin{array}{l}\text { SCCAI }(\text { mean } \pm \text { SD) severity, } \\
\text { SCCAI }\end{array}$ & $3.83 \pm 3.16$ & $3.78 \pm 3.12$ & $3.95 \pm 3.26$ \\
\hline \multicolumn{4}{|l|}{ Use of corticosteroids } \\
\hline Yes & $120(39.1)$ & $65(31.1)$ & $55(56.1)$ \\
\hline No & $187(60.9)$ & $144(68.9)$ & $43(43.9)$ \\
\hline \multicolumn{4}{|c|}{ Clinical response to corticosteroids } \\
\hline Yes & $30(9.8)$ & $18(8.6)$ & $12(12.2)$ \\
\hline No & $277(90.2)$ & $191(91.4)$ & $86(87.8)$ \\
\hline \multicolumn{4}{|l|}{ Anaemia } \\
\hline Yes & $88(28.7)$ & $48(23.0)$ & $40(40.8)$ \\
\hline No & $219(71.3)$ & $161(77.0)$ & $58(59.2)$ \\
\hline \multicolumn{4}{|l|}{ EIM } \\
\hline Yes & $25(8.1)$ & $13(6.2)$ & $12(12.2)$ \\
\hline No & $282(91.9)$ & $196(93.8)$ & $86(87.8)$ \\
\hline \multicolumn{4}{|l|}{ Smoking } \\
\hline Yes & $48(15.6)$ & $37(17.7)$ & $11(11.2)$ \\
\hline No & $259(84.4)$ & $172(82.3)$ & $87(88.8)$ \\
\hline \multicolumn{4}{|l|}{ Former smoker } \\
\hline Yes & $76(24.8)$ & $55(26.3)$ & $21(21.4)$ \\
\hline No & $231(75.2)$ & $154(73.7)$ & 77 (78.6) \\
\hline \multicolumn{4}{|l|}{ Mayo endoscopic subscore, 3} \\
\hline Yes & $55(17.9)$ & $28(13.4)$ & $27(27.6)$ \\
\hline No & $252(82.1)$ & $181(86.6)$ & $71(72.4)$ \\
\hline \multicolumn{4}{|l|}{ Thrombocytosis } \\
\hline Yes & $43(14.0)$ & $28(13.4)$ & $15(15.3)$ \\
\hline No & $264(86.0)$ & $181(86.6)$ & $83(84.7)$ \\
\hline
\end{tabular}

All data are $n(\%)$ unless otherwise stated

EIM extraintestinal manifestations, SCCAI simple clinical colitis activity index 
Table 5 Uni- and multivariate Cox regression analysis for predictive factors of complicated disease course $(n=307)$

\begin{tabular}{|c|c|c|c|c|}
\hline \multirow[t]{2}{*}{ Factor, risk } & \multicolumn{2}{|l|}{ Univariate analysis } & \multicolumn{2}{|c|}{ Multivariate analysis, complete model } \\
\hline & Hazard ratio (95\% CI) & $p$ value & Hazard ratio $(95 \% \mathrm{CI})$ & $p$ value \\
\hline Age, years & $0.983(0.969-0.997)$ & 0.014 & $0.985(0.971-1.000)$ & 0.047 \\
\hline Sex, male & $1.517(1.007-2.286)$ & 0.044 & $1.490(0.980-2.267)$ & 0.062 \\
\hline Disease severity, SCCAI & $1.035(0.974-1.099)$ & 0.273 & $1.038(0.977-1.103)$ & 0.227 \\
\hline Corticosteroids, yes & $2.540(1.700-3.795)$ & $<0.001$ & $2.085(1.318-3.299)$ & 0.002 \\
\hline Clinical response to corticosteroids, no & $1.505(0.822-2.755)$ & 0.208 & $1.074(0.555-2.077)$ & 0.832 \\
\hline Anaemia, yes & $2.200(1.467-3.298)$ & $<0.001$ & $1.995(1.265-3.145)$ & $\mathbf{0 . 0 0 3}$ \\
\hline EIM, yes & $1.699(0.928-3.112)$ & 0.108 & $1.661(0.883-3.124)$ & 0.115 \\
\hline Smoking, yes & $0.638(0.341-1.196)$ & 0.137 & $0.601(0.316-1.140)$ & 0.119 \\
\hline Former smoker, yes & $0.858(0.529-1.391)$ & 0.535 & $1.068(0.637-1.790)$ & 0.803 \\
\hline Mayo endoscopic subscore $=3$, yes & $1.863(1.188-2.921)$ & 0.007 & $1.251(0.776-2.015)$ & 0.358 \\
\hline Thrombocytosis, yes & $1.262(0.728-2.189)$ & 0.407 & $0.712(0.380-1.334)$ & 0.288 \\
\hline
\end{tabular}

EIM extraintestinal manifestations, SCCAI simple clinical colitis activity index

Based on the two parameters (therapy with systemic corticosteroids and anaemia), a predictive risk model was developed to determine the individual patient's likelihood of experiencing a complicated disease course at 6,12 , or 24 months (Table 7).

\section{Discussion}

EPICOL was a prospective study on a large inception cohort of patients with UC to identify early predictors for a complicated disease course.

We found that approximately one third (98/311 [31.6\%]) of all patients in our study received IS and/or biologic treatment. Only one patient was admitted to the hospital; this admission occurred after the 24-month follow-up period. A possible explanation for the low number of hospitalisations is that our study was conducted exclusively at specialised IBD centres and, therefore, tighter disease management may have been observed, resulting in a lower hospitalisation rate. This may also be reflected in the high number of unscheduled visits to physicians, which enabled immediate therapeutic changes where necessary, thereby potentially avoiding hospitalisations. This notion is supported by the fact that the mean SCCAI score of our cohort declined continuously over the course of this study, reaching a value of $1.3 \pm 2.1$ at the end of the follow-up period. It is also worth mentioning that other studies have found that EIMs may be present in up to $25 \%$ of patients with IBD before diagnosis [25], which is significantly higher than the $\sim 7 \%$ of patients in our cohort who reported EIMs in their disease history. We speculate that this lower rate of EIMs reported before diagnosis may, at least in part, be caused by the fact that EIMs were not the primary methodologic concern of this study, leading to some degree of underreporting compared with other studies that focused particularly on EIMs.

The most important finding of our study is that prior use of corticosteroids or anaemia at diagnosis were associated with a significantly higher risk for a complicated disease course, defined as need for treatment with IS and/ or biologics and/or UC-related hospitalisation. Although numerous studies have already found an association between prior corticosteroid use and poorer outcomes, most were either retrospective [17, 18, 26-28]; addressed other outcomes, such as risk for colectomy or proximal
Table 6 Reduced and optimised Cox regression analysis for predictive factors of complicated disease course $(n=307)$

\begin{tabular}{|c|c|c|c|c|}
\hline \multirow[t]{3}{*}{ Factor, risk } & \multicolumn{4}{|l|}{ Multivariate analysis } \\
\hline & \multicolumn{2}{|l|}{ Reduced model } & \multicolumn{2}{|l|}{ Optimised model } \\
\hline & Hazard ratio $(95 \% \mathrm{CI})$ & $p$ value & Hazard ratio (95\%CI) & $p$ value \\
\hline Age, years & $0.987(0.973-1.001)$ & 0.079 & - & - \\
\hline Sex, male & $1.448(0.959-2.188)$ & 0.078 & - & - \\
\hline Corticosteroids, yes & $2.027(1.321-3.111)$ & 0.001 & $2.326(1.550-3.491)$ & $<0.001$ \\
\hline Anaemia, yes & $1.784(1.171-2.718)$ & 0.007 & $1.940(1.288-2.922)$ & 0.002 \\
\hline $\begin{array}{l}\text { Mayo endoscopic sub- } \\
\text { score }=3 \text {, yes }\end{array}$ & $1.361(0.851-2.178)$ & 0.198 & - & - \\
\hline
\end{tabular}


Table 7 Risk model for prediction of complicated disease course

\begin{tabular}{|c|c|c|c|}
\hline Time & Corticosteroids & Anaemia & $\begin{array}{l}\text { Probability } \\
\text { of IS, } \%\end{array}$ \\
\hline \multirow[t]{4}{*}{ After 6 months } & No & No & 10.5 \\
\hline & Yes & No & 15.1 \\
\hline & No & Yes & 13.7 \\
\hline & Yes & Yes & 19.6 \\
\hline \multirow[t]{4}{*}{ After 12 months } & No & No & 17.0 \\
\hline & Yes & No & 24.0 \\
\hline & No & Yes & 21.9 \\
\hline & Yes & Yes & 30.7 \\
\hline \multirow[t]{4}{*}{ After 24 months } & No & No & 23.0 \\
\hline & Yes & No & 32.1 \\
\hline & No & Yes & 29.5 \\
\hline & Yes & Yes & 40.3 \\
\hline
\end{tabular}

disease extension [18, 26-29]; or could not validate prior corticosteroid use as an independent predictor in rigorous multivariate analysis [26]. To the best of our knowledge, this is, therefore, the first prospective study that demonstrates early use of corticosteroids as an independent predictor of requiring treatment with IS and/or biologics and/ or hospitalisation.

Based on our findings, we developed a risk model for the prediction of a complicated disease course in 6,12 , and 24 months after baseline for recently diagnosed patients with UC. In this model, the previous use of corticosteroids and/or anaemia increases the risk of immunosuppressive therapy after 6 months to $>13 \%$. The likelihood of a complicated disease course occurring after 12 and 24 months is quite high, ranging from $21.9 \%$ (after 12 months with anaemia) to $40.3 \%$ (after 24 months with previous corticosteroid use and anaemia). With regard to the risk model that we developed for patients with $\mathrm{CD}$, it is interesting that an age at onset of $<40$ years was identified as risk factor as well as anaemia and corticosteroid use. However, the rather low number of patients with UC with a complicated disease course in our cohort is in line with published results demonstrating a less complicated disease course for patients with UC in a certain time frame compared with patients with $\mathrm{CD}$ [30]. Both models are suitable for identifying patients at risk for a more complex disease course. Certainly, further verification of our models incorporating independent patient cohorts is required in future.

Multiple studies have already revealed an association between anaemia and unfavourable disease events, such as corticosteroid utilisation [31], corticosteroid-refractory disease [32], colectomy [33, 34], and relapse following aminosalicylate treatment [35]. As in the case of corticosteroid use, these were, however, mostly retrospective analyses. Our study thus provides validation of the predictive power of anaemia within a prospective setting. Interestingly, anaemia was also an independent predictor of a complicated disease course in our EPIC study on patients with recently diagnosed CD [24]. The cause of anaemia in IBD is multifactorial, with important factors being blood loss through active UC, impaired iron absorption, and utilisation caused by chronic inflammation as well as reduced intake and, less frequently, vitamin B12 deficiency [36]. Because we did not observe a baseline difference in the SCCAI parameter "blood in stool" between our two groups (data not shown), it could be speculated that, in our cohort, an anaemic state at baseline or diagnosis reflects reduced iron absorption rather than secondary blood loss, which could in turn explain the predictive power of this parameter.

However, given the general scarcity and limited suitability of prospective studies describing clinical predictors for recently diagnosed patients, it seems worth posing the question as to how far the disease course can be accurately predicted solely based on clinical parameters. Future studies will need to address this issue and investigate whether genomic, transcriptomic, and microbiomic profiling approaches can achieve a greater predictive power than clinical parameters alone.

The main strengths of our study are its prospective and multi-centre design, the high number of patients and study centres, as well as the short time interval between diagnosis and enrolment. Nonetheless, there are several limitations. One limitation is that the investigations were conducted exclusively at IBD-specialised centres, meaning that patients treated by primary care physicians were not included in this study. As a result, we cannot exclude the possibility that different or additional predictors may be relevant in patients treated at centres with less therapeutic experience. In addition, a substantial fraction of all measurements were not available in some cases, limiting our analysis to sufficiently well-reported parameters.

In summary, this thoroughly designed, large, prospective inception cohort study of patients with UC determined clinical predictors that are easy to assess in everyday clinical practice and provided important evidence for the risk stratification of patients with recently diagnosed UC.

Supplementary information The online version contains supplementary material available at https://doi.org/10.1007/s00384-022-04098-7.

Acknowledgements AbbVie and the authors thank the patients who participated in this study. The authors also thank all members of the EPICOL Study Group for their contribution to the success of the study. The members of the EPICOL study group are listed in the Supplemental Material.

Authors' contribution Study concept and design: C Schmidt, B Bokemeyer, D Bettenworth, N Teich, A Stallmach, A Lügering, S Kolterer, S Rath. Analysis: I Fischer. Interpretation of data: C Schmidt, B Bokemeyer, D Bettenworth, N Teich, A Stallmach, A Lügering, L Hammer, S Kolterer, S 
Rath. Drafting of the manuscript: C Schmidt, B Bokemeyer, D Bettenworth, N Teich, A Stallmach, A Lügering, L Hammer, S Kolterer, S Rath. Critical revision of the manuscript for important intellectual content and approval of the final version: C Schmidt, B Bokemeyer, D Bettenworth, N Teich, A Stallmach, A Lügering, L Hammer, S Kolterer, S Rath.

Funding Open Access funding enabled and organized by Projekt DEAL. AbbVie sponsored the study; contributed to the design; participated in the collection, analysis, and interpretation of data; in writing, reviewing, and approval of the final version. Statistical analysis support was provided by Dr. Imma Fischer, Biostatistik Tübingen, which was funded by AbbVie. No honoraria or payments were made for authorship.

Data availability All data and materials support the claims in this manuscript and comply with field standards.

\section{Declarations}

Ethics approval The protocol of this study was in accordance with ethical standards as laid down by the ethics committee of the Jena University Hospital (4102-06/14). The study was performed in accordance with the principles of the Declaration of Helsinki and its later amendments.

Consent to participate Freely given, informed consent was obtained in written form from all individual participants before their inclusion in the study.

Conflict of interest C Schmidt obtained consulting fees from AbbVie, Amgen, Biogen, Ewopharma, Galapagos, Janssen, MSD, Pfizer, and Takeda; lecture fees and travel support from AbbVie, Berlin Chemie, Biogen, CED Service, Ewopharma, Falk, Janssen, Med Update, Merckle, MSD Sharp \& Dohme, Norgine, Novartis, Olympus, Pentax, Pfizer, Shire, Shield Therapeutics, and Takeda; and research support from AbbVie, Olympus, and Pentax. B Bokemeyer has received consulting fees from AbbVie, MSD, Shire, Ferring, UCB, Hospira, Takeda, Movetis, Shield Therapeutics, Pfizer, Biogen, Janssen, Hexal, Cellgene, Boehringer, Allergan, Galapagos, and Celltrion; has provided speaking and teaching services for AbbVie, Ferring, MSD, Merckle, Falk, HLR, UCB, Shield Therapeutics, Pfizer, Celltrion, Takeda, Janssen, Mundipharma, and Tillotts; and has received grants and research funding form AbbVie, Ferring, UCB, Given Imaging, Janssen, Takeda, Pfizer, and Galapagos. D Bettenworth is on the advisory board or a consultant for AbbVie, Amgen, Arena, Bristol Myers Squibb, Celltrion, Else KrönerFresenius-Stiftung, Dr. Falk Foundation, Ferring, Galapagos, Guidepoint, MSD, Medical Tribune, Pfizer, Pharmacosmos, Roche, Takeda, Thieme, Tillotts Pharma, Viatris, and Vifor. I Fischer has received consulting fees from AbbVie. N Teich reports personal fees from AbbVie, Celltrion, Falk Foundation, Janssen, MSD, Takeda, and Pfizer outside the submitted work. A Stallmach reports research funding from AbbVie and Celltrion and has received lecture fees from AbbVie, Amgen, Astellas, Biogen, Celltrion, Institut Allergosan, Janssen, Falk Foundation, Ferring, MSD, RecordatiPharma, Streamed-Up, and Takeda and consulting fees from AbbVie, Astellas, Amgen, Biogen, CLS Behring, Consal, Galapagos, Hexal, Janssen, MSD, Norgine, Pfizer Pharma, Takeda, and Tillotts Pharma. A Lügering has received advisory board or consulting fees from AbbVie, Ferring, Janssen, MSD, Pfizer, Takeda, and Tillotts Pharma. L Hammer, S Kolterer, and S Rath are AbbVie employees and may own AbbVie stock or options.

Open Access This article is licensed under a Creative Commons Attribution 4.0 International License, which permits use, sharing, adaptation, distribution and reproduction in any medium or format, as long as you give appropriate credit to the original author(s) and the source, provide a link to the Creative Commons licence, and indicate if changes were made. The images or other third party material in this article are included in the article's Creative Commons licence, unless indicated otherwise in a credit line to the material. If material is not included in the article's Creative Commons licence and your intended use is not permitted by statutory regulation or exceeds the permitted use, you will need to obtain permission directly from the copyright holder. To view a copy of this licence, visit http://creativecommons.org/licenses/by/4.0/.

\section{References}

1. Feuerstein JD, Moss AC, Farraye FA (2019) Ulcerative colitis. Mayo Clin Proc 94(7):1357-1373

2. Silverberg MS, Satsangi J, Ahmad T, Arnott ID, Bernstein CN, Brant SR et al (2015) Toward an integrated clinical, molecular and serological classification of inflammatory bowel disease: report of a working party of the 2005 Montreal World Congress of Gastroenterology. Can J Gastroenterol 19 Suppl A:5a-36a

3. Magro F, Rodrigues A, Vieira AI, Portela F, Cremers I, Cotter J et al (2011) Review of the disease course among adult ulcerative colitis population-based longitudinal cohorts. Inflamm Bowel Dis 18(3):573-583

4. Solberg IC, Lygren I, Jahnsen J, Aadland E, Høie O, Cvancarova $\mathrm{M}$ et al (2009) Clinical course during the first 10 years of ulcerative colitis: results from a population-based inception cohort (IBSEN study). Scand J Gastroenterol 44(4):431-440

5. Updated S3-guideline ulcerative colitis (2019) German Society for Digestive and Metabolic Diseases (DGVS). Z Gastroenterol 57(2):162-241

6. Feuerstein JD, Isaacs KL, Schneider Y, Siddique SM, Falck-Ytter Y, Singh S et al (2020) AGA clinical practice guidelines on the management of moderate to severe ulcerative colitis. Gastroenterology 158(5):1450-1461

7. Gordon IO, Agrawal N, Willis E, Goldblum JR, Lopez R, Allende $\mathrm{D}$ et al (2018) Fibrosis in ulcerative colitis is directly linked to severity and chronicity of mucosal inflammation. Aliment Pharmacol Ther 47(7):922-939

8. Torres J, Billioud V, Sachar DB, Peyrin-Biroulet L, Colombel JF (2012) Ulcerative colitis as a progressive disease: the forgotten evidence. Inflamm Bowel Dis 18(7):1356-1363

9. Solitano V, D'Amico F, Zacharopoulou E, Peyrin-Biroulet L, Danese S (2020) Early intervention in ulcerative colitis: ready for prime time? J Clin Med 9(8)

10. Turner D, Ricciuto A, Lewis A, D'Amico F, Dhaliwal J, Griffiths AM et al (2020) STRIDE-II: an update on the selecting therapeutic targets in inflammatory bowel disease (STRIDE) initiative of the International Organization for the Study of IBD (IOIBD): determining therapeutic goals for treat-to-target strategies in IBD. Gastroenterology

11. Danese S, Colombel JF, Peyrin-Biroulet L, Rutgeerts P, Reinisch W (2013) Review article: the role of anti-TNF in the management of ulcerative colitis - past, present and future. Aliment Pharmacol Ther 37(9):855-866

12. Torres J, Caprioli F, Katsanos KH, Lobaton T, Micic D, Zeroncio M et al (2016) Predicting outcomes to optimize disease management in inflammatory bowel diseases. J Crohns Colitis 10(12):1385-1394 
13. Siegel CA, Bernstein CN (2020) Identifying patients with inflammatory bowel diseases at high vs low risk of complications. Clin Gastroenterol Hepatol 18(6):1261-1267

14. Targownik LE, Singh H, Nugent Z, Bernstein CN (2012) The epidemiology of colectomy in ulcerative colitis: results from a population-based cohort. Am J Gastroenterol 107(8):1228-1235

15. Gower-Rousseau C, Dauchet L, Vernier-Massouille G, Tilloy E, Brazier F, Merle V et al (2009) The natural history of pediatric ulcerative colitis: a population-based cohort study. Am J Gastroenterol 104(8):2080-2088

16. Dinesen LC, Walsh AJ, Protic MN, Heap G, Cummings F, Warren BF et al (2010) The pattern and outcome of acute severe colitis. J Crohns Colitis 4(4):431-437

17. Cesarini M, Collins GS, Rönnblom A, Santos A, Wang LM, Sjöberg D et al (2017) Predicting the individual risk of acute severe colitis at diagnosis. J Crohns Colitis 11(3):335-341

18. Samuel S, Ingle SB, Dhillon S, Yadav S, Harmsen WS, Zinsmeister AR et al (2013) Cumulative incidence and risk factors for hospitalization and surgery in a population-based cohort of ulcerative colitis. Inflamm Bowel Dis 19(9):1858-1866

19. Hoie O, Wolters FL, Riis L, Bernklev T, Aamodt G, Clofent J et al (2007) Low colectomy rates in ulcerative colitis in an unselected European cohort followed for 10 years. Gastroenterology 132(2):507-515

20. Ananthakrishnan AN, Issa M, Beaulieu DB, Skaros S, Knox JF, Lemke K et al (2009) History of medical hospitalization predicts future need for colectomy in patients with ulcerative colitis. Inflamm Bowel Dis 15(2):176-181

21. Borren NZ, Khalili H, Luther J, Colizzo FP, Garber JJ, Ananthakrishnan AN (2019) Second-look endoscopy in hospitalized severe ulcerative colitis: a retrospective cohort study. Inflamm Bowel Dis 25(4):750-755

22. Paredes Méndez JE, Alosilla Sandoval PA, Quiroga Purizaca WG, Mestanza Rivasplata AL, Cieza Mestanza V, Vargas Marcacuzco $\mathrm{H}$ et al (2019) Evaluation of endoscopic and histological activity as predictors of clinical relapse in ulcerative colitis. Rev Gastroenterol Peru 39(3):223-228

23. Dassopoulos T, Cohen RD, Scherl EJ, Schwartz RM, Kosinski L, Regueiro MD (2015) Ulcerative colitis care pathway. Gastroenterology 149(1):238-245

24. Stallmach A, Bokemeyer B, Helwig U, Lugering A, Teich N, Fischer I et al (2019) Predictive parameters for the clinical course of Crohn's disease: development of a simple and reliable risk model. Int J Colorectal Dis 34(10):1653-1660

25. Vavricka SR, Rogler G, Gantenbein C, Spoerri M, Prinz Vavricka M, Navarini AA et al (2015) Chronological order of appearance of extraintestinal manifestations relative to the time of IBD diagnosis in the Swiss inflammatory bowel disease cohort. Inflamm Bowel Dis 21(8):1794-1800
26. Kim B, Park SJ, Hong SP, Kim TI, Kim WH, Cheon JH (2014) Proximal disease extension and related predicting factors in ulcerative proctitis. Scand J Gastroenterol 49(2):177-183

27. Meucci G, Vecchi M, Astegiano M, Beretta L, Cesari P, Dizioli $P$ et al (2000) The natural history of ulcerative proctitis: a multicenter, retrospective study. Gruppo di Studio per le Malattie Infiammatorie Intestinali (GSMII). Am J Gastroenterol 95(2):469-73

28. Khan NH, Almukhtar RM, Cole EB, Abbas AM (2014) Early corticosteroids requirement after the diagnosis of ulcerative colitis diagnosis can predict a more severe long-term course of the disease - a nationwide study of 1035 patients. Aliment Pharmacol Ther 40(4):374-381

29. Solberg IC, Hoivik ML, Cvancarova M, Moum B, Group IS (2015) Risk matrix model for prediction of colectomy in a population-based study of ulcerative colitis patients (the IBSEN study). Scand J Gastroenterol 50(12):1456-62

30. Burisch J, Jess T, Martinato M, Lakatos PL, EpiCom oboE (2013) The burden of inflammatory bowel disease in Europe. J Crohn's Colitis 7(4):322-37

31. Khan N, Patel D, Shah Y, Lichtenstein G, Yang YX (2017) A novel user-friendly model to predict corticosteroid utilization in newly diagnosed patients with ulcerative colitis. Inflamm Bowel Dis 23(6):991-997

32. Chow DK, Sung JJ, Tsoi KK, Wong VW, Wu JC, Leong RW et al (2009) Predictors of corticosteroid-dependent and corticosteroidrefractory inflammatory bowel disease: analysis of a Chinese cohort study. Aliment Pharmacol Ther 29(8):843-854

33. Abou Khalil M, Boutros M, Nedjar H, Morin N, Ghitulescu G, Vasilevsky CA et al (2018) Incidence rates and predictors of colectomy for ulcerative colitis in the era of biologics: results from a provincial database. J Gastrointest Surg 22(1):124-132

34. Ananthakrishnan AN, McGinley EL, Binion DG, Saeian K (2010) Simple score to identify colectomy risk in ulcerative colitis hospitalizations. Inflamm Bowel Dis 16(9):1532-1540

35. Lee HJ, Jung ES, Lee JH, Hong SP, Kim TI, Kim WH et al (2012) Long-term clinical outcomes and factors predictive of relapse after 5-aminosalicylate or sulfasalazine therapy in patients with mild-to-moderate ulcerative colitis. Hepatogastroenterology 59(117):1415-1420

36. Stein J, Dignass AU (2013) Management of iron deficiency anemia in inflammatory bowel disease - a practical approach. Ann Gastroenterol 26(2):104-113

Publisher's Note Springer Nature remains neutral with regard to jurisdictional claims in published maps and institutional affiliations. 